\title{
Correction to: Mechanical properties of wire and arc additively manufactured high-strength steel structures
}

\author{
Johanna Müller $^{1}$ D $\cdot$ Jonas Hensel ${ }^{1} \cdot$ Klaus Dilger $^{1}$
}

Published online: 18 February 2022

(c) The Author(s) 2022

\section{Correction to: Welding in the World (2021) 66:395-407 https://doi.org/10.1007/s40194-021-01204-1}

The original version of this article unfortunately contained a mistake. Figure 9 was not correct, the figure should have appeared as shown below.

The original article has been corrected.

Open Access This article is licensed under a Creative Commons Attribution 4.0 International License, which permits use, sharing, adaptation, distribution and reproduction in any medium or format, as long

as you give appropriate credit to the original author(s) and the source, provide a link to the Creative Commons licence, and indicate if changes were made. The images or other third party material in this article are included in the article's Creative Commons licence, unless indicated otherwise in a credit line to the material. If material is not included in the article's Creative Commons licence and your intended use is not permitted by statutory regulation or exceeds the permitted use, you will need to obtain permission directly from the copyright holder. To view a copy of this licence, visit http://creativecommons.org/licenses/by/4.0/.

Publisher's note Springer Nature remains neutral with regard to jurisdictional claims in published maps and institutional affiliations.

The original article can be found online at https://doi.org/10.1007/ s40194-021-01204-1.

Johanna Müller

johanna.mueller@tu-braunschweig.de

1 Institute of Joining and Welding, TU Braunschweig, Langer

Kamp 8, 38106 Braunschweig, Germany 

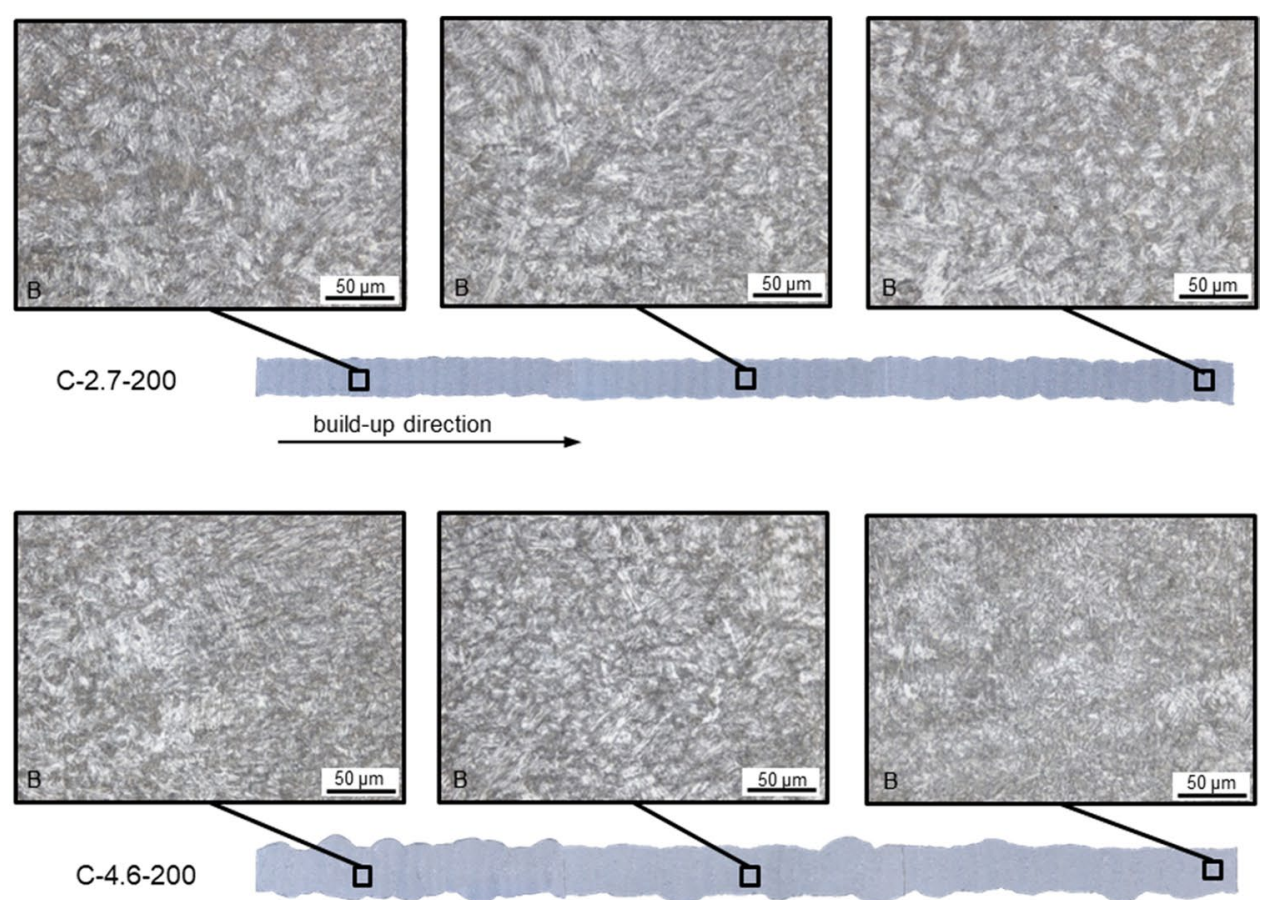

build-up direction
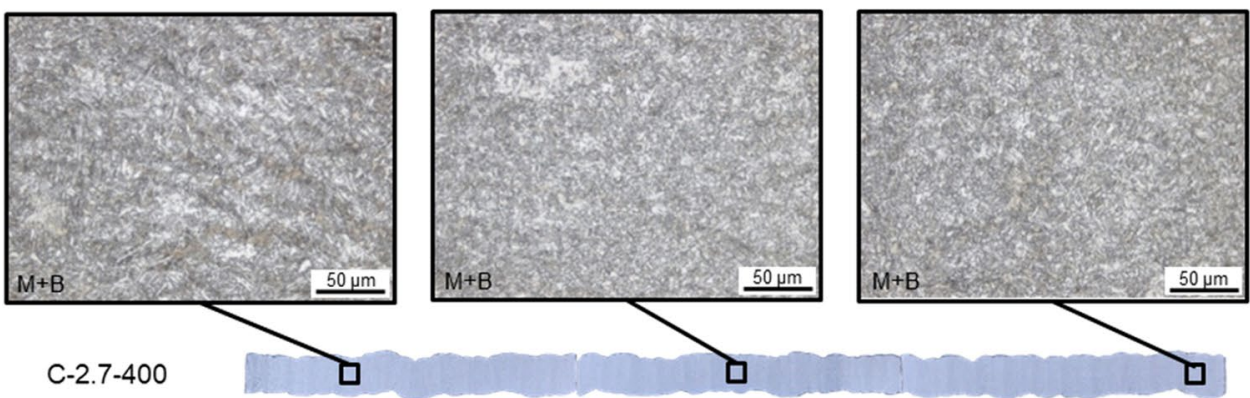

build-up direction
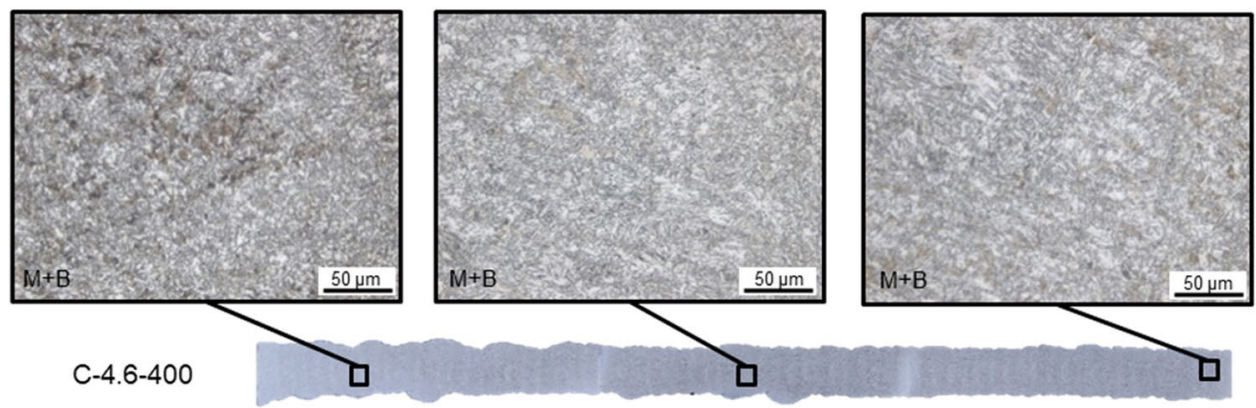

build-up direction 